\title{
La consulta previa desde la perspectiva de la negociación deliberativa**
}

\author{
The prior consultation from the \\ deliberative negotiation perspective
}

SUMARIO

Introducción. 1. La consulta previa: concepto, características y dificultades. 2. El paso de un escenario de negociación coercitiva a un escenario de negociación deliberativa. 2.1. La consulta previa como un escenario deliberativo de expresión del interés individual.2.2. El consenso y la clarificación (o estructuración) del conflicto como finalidades principal y secundaria de la deliberación. Conclusiones.

\section{RESUMEN}

La consulta previa, como una de las herramientas de protección de los derechos de los grupos étnicos más emblemáticas por su talante participativo, presenta sin embargo una construcción normativa y doctrinal que no comulga con la democracia deliberativa, principalmente porque supone, primero, la expresión de intereses individuales por parte de los participantes y, segundo, la posibilidad de que una de las partes ejerza algún tipo de poder sobre la otra para influir en el resultado. No obstante lo anterior, la reformulación del ideal deliberativo clásico por parte de una corriente de pensamiento que ve la posibilidad de hallar en este concepto un espacio para la expresión de intereses individuales y el ejercicio de poder bajo ciertas circunstancias, permite proponer una nueva visión de la consulta previa que la puede conducir a ser un escenario de intercambio cultural, que supere los escollos que esta figura presenta en la práctica cotidiana.

\footnotetext{
* Docente e investigador del Departamento de Derecho Constitucional de la Universidad Externado de Colombia, abogado de esta misma universidad y magíster en Derechos Humanos de la Università di Bologna, Italia. Actualmente es estudiante de doctorado en Derecho Constitucional de la Universidad de Buenos Aires.Contacto: alejandro.santamaria@uexternado.edu.co

** Recibido el 31 de julio de 2015, aprobado el 16 de mayo de 2016.

Para citar el artículo: A. SANTAMARÍA Ortiz, La consulta previa desde la perspectiva de la negociación deliberativa, Derecho del Estado n. . $^{\circ}$ 6, Universidad Externado de Colombia, enerojunio de 2016, pp. 227-247. Dor: http://dx.doi.org/10.18601/01229893.n36.08.
} 
PALABRAS CLAVE

Consulta previa, democracia deliberativa, participación, negociación deliberativa, pueblos indígenas, identidad cultural.

\section{ABSTRACT}

Notwithstanding the prior consultation is one of the most emblematic protection tools of the indigenous peoples' rights; it presents a regulative and doctrinal construction which not sympathizes with the deliberative democracy ideal; firstly, because of the expression of individual interests and secondly for the possibility that one of the parties could exercise some kind of power over the other to influence the result. A direction of thought has reformulated the classic deliberative ideal to allow the possibility of finding in this concept a space for the expression of self-interest and the exercise of power, under certain circumstances. These changes in the concept of deliberation allow us to propose a new vision of the prior consultation, which transforms it in a space for cultural exchange overcoming the obstacles that are present in daily practice.

KEYWORDS

Prior consultation, deliberative democracy, participation, deliberative negotiation, indigenous peoples, cultural identity.

\section{INTRODUCCIÓN}

La "consulta previa" representa uno de los principales triunfos del derecho internacional de los derechos humanos para la protección de los grupos étnicos. Se trata de una manifestación del derecho de participación, una aplicación del principio democrático, que supone que los destinatarios de una decisión participen en su confección y en la forma de su ejecución, la cual se ha convertido en una importante herramienta de protección de las comunidades o pueblos indígenas y tribales.

La reivindicación de su territorio, de su autonomía política, administrativa y jurisdiccional es uno de los escenarios en que se puede evidenciar el ejercicio de esta figura democrática, la cual se ha erigido como un derecho en cabeza del colectivo indígena y su identidad cultural.

No obstante lo anterior, los Estados que han reconocido esta garantía en sus ordenamientos jurídicos no han logrado dotarla de una real eficacia. Al parecer, muchos de estos privilegian la explotación de sus recursos naturales por encima de los intereses de las comunidades aborígenes que allí habitan. En Latinoamérica hay varios ejemplos de este fenómeno, algunos de los cuales 
han tenido trascendencia internacional, como es el caso de la explotación petrolera en el Amazonas ecuatoriano que perjudicó la comunidad Sarayaku y que terminó en una sentencia de la Corte Interamericana de Derechos Humanos, decisión que protegió el derecho a la propiedad de este pueblo aborigen (Pueblo Indígena Kichwa de Sarayaku vs. Ecuador. Sentencia de 27 de junio de 2012) ${ }^{1}$.

En Colombia esta figura existe desde la integración al ordenamiento jurídico del Convenio 169 de 1989 de la oIT, suscrito y ratificado mediante la Ley 21 de 1991, pero fue la Corte Constitucional, de la mano del texto constitucional y su amplia protección de los pueblos aborígenes, la que logró transformarla en la principal garantía de la autodeterminación de los pueblos originarios, con su inclusión dentro del catálogo de derechos fundamentales susceptibles de protección mediante la acción de tutela. Esta posición ha sido la principal aliada de los indígenas y pueblos afrodescendientes en contra de decisiones inconsultas sobre explotación forestal ${ }^{2}$, exploración y explotación de petróleo ${ }^{3}$, construcción de proyectos hidroeléctricos ${ }^{4}$, proyectos de concesión minera ${ }^{5}$, entre otros.

Es así como, mientras los pueblos étnicos ven la consulta previa como una valiosa herramienta en su favor y se aferran a ella como su principal aliada para la defensa de su identidad cultural, los gobiernos encuentran en esta un escollo, un obstáculo para el desarrollo económico del país. Por ejemplo, en entrevista con el diario El Tiempo, el vicepresidente de Colombia, GERMÁn VARGAS LLERAS, en el año 2014, al describir las nuevas competencias asumidas por su cargo en materia de desarrollo de infraestructura, y específicamente respecto de la "doble calzada Buga-Buenaventura" (una obra pública en particular), dijo de manera expresa que "las consultas previas están frenando y paralizando la ejecución de esas obras”, y finalizó con la afirmación de que "no se puede continuar abusando de esa figura y retrasando indebidamente la ejecución" de tales proyectos ${ }^{6}$.

El objetivo de este escrito es aportar un enfoque que pueda ayudar a cambiar esta perspectiva conflictiva con la que se aborda la figura de la consulta previa, y que los Estados y minorías étnicas puedan apreciarla como una herramienta con mayor nivel democrático; como un espacio dialógico en el

1 Dentro de la jurisprudencia de la Corte Interamericana, en materia de consulta previa el caso citado tiene un importante antecedente en la sentencia del 28 de noviembre de 2007 en el caso Pueblo Saramaka vs. Surinam (Excepciones Preliminares, Fondo, Reparaciones y Costas).

2 Sentencia T-380 de 1993, M.P.: Eduardo Cifuentes MuÑoz.

3 Sentencia SU-039 de 1997, M.P.: Antonio Barrera Carbonell.

4 Sentencia T-652 de 1998, M.P.: Carlos Gaviria Díaz.

5 Sentencia T-769 de 2009, M.P.: Nilson Pinilla PinIlla.

6 No se puede seguir abusando de la consulta previa: VARGAS Lleras. El Tiempo. Bogotá, 18 de agosto de 2014. Consultado el 10 de julio de 2015 en: http://www.eltiempo.com/politica/ gobierno/entrevista-de-el-tiempo-a-german-vargas-lleras/14402995 
que cada participante pueda exponer sus posiciones, bajo estándares deliberativos, y en donde se logre llegar a un consenso o, al menos, a la delimitación de los puntos irresolubles bajo debate.

En concreto, propongo ver la consulta previa como un escenario de "negociación deliberativa", de acuerdo con el concepto acuñado en el estudio conducido por la profesora de Harvard JANE MANSBRIDGE y otros importantes autores, titulado The Place of Self-Interest and the Role of Power in Deliberative Democracy (El lugar del interés individual y el rol del poder en la democracia deliberativa $)^{7}$. Allí se plantea un escenario deliberativo de negociación sin coerción que, bajo estrictos parámetros, permite a los participantes expresar sus intereses individuales y el uso del poder, con el objetivo de que aún bajo estas condiciones se pueda considerar este como un escenario deliberativo ${ }^{8}$.

La expresión del interés individual dentro de un diálogo deliberativo donde se busca el bien común, en principio, supondría una contradicción, de la misma forma que el ejercicio de cualquier tipo de poder por los participantes, ello en cuanto que sería esto y no la racionalidad lo que guiaría el debate. Sin embargo, los mencionados autores advierten que una dosis de ambos elementos puede ser compatible con la deliberación, e incluso necesaria en algunos casos.

En este sentido, si bien la consulta previa se ha convertido en un escenario de abierta confrontación, considero que de la mano de la debida conducción de los intereses que defienden las partes y de la limitación de la capacidad de ejercer poder que estas en un momento determinado puedan poseer, es posible aspirar a convertirla en un espacio de "negociación deliberativa" y, de esa forma, mantener la amenaza de imposición de una parte sobre otra como última opción. Con este propósito, el escrito se dividirá en dos partes; en la primera, se expondrá el concepto de consulta previa, sus características y algunos de los inconvenientes que ha tenido en su puesta en práctica; en la segunda, se mostrará cómo la deliberación es compatible con la expresión de intereses individuales, y cómo el cambio normativo de las finalidades de la figura pueden transformarla desde su raíz.

7 Mansbridge, J.; Bohman, J.; Chambers, S.; Estlund, D.; Føllesdal, A.; Fung, A.; Lafont, C.; Manin, B. y Martí, J. L. The Place of Self-Interest and the Role of Power in Deliberative Democracy. The Journal of Political Philosophy. Vol. 18, n. ${ }^{\circ}$ 1, 2010, 64-100.

8 A continuación transcribo la nota al pie que se presenta en el título del artículo en mención y que muestra el enorme esfuerzo que representa su contenido: "This article was primarily written by Jane Mansbridge, drawing on ideas and concerns common to the group of co-authors shared through meetings, conversation, correspondence, and (yes) deliberation. It was revised on a rolling basis to incorporate the suggestions of co-authors. Although each co-author would, if writing independently, put things in his or her own way, the paper represents a direction of thought the co-authors collectively endorse": ibíd., 64. 
La primera aproximación internacional a la protección de los pueblos indígenas y tribales la dio la Organización Internacional del Trabajo (огт), en el Convenio 107 de 1957. Este fue el primer instrumento normativo, vinculante, que fijó las obligaciones de los Estados parte en materia de la atención de las comunidades étnicas. Sin embargo, su enfoque era "integracionista", es decir, "se basa[ba] en el supuesto [de] que los pueblos indígenas y tribales eran sociedades temporarias destinadas a desaparecer con la modernización"".

Esta organización internacional encaró nuevamente el tema desde los años setenta, debido a las constantes críticas que su enfoque había traído y por la visibilidad internacional que los pueblos originarios habían cobrado. Por esta razón, se redactó un nuevo convenio que se basó en el derecho a la autodeterminación de los pueblos, el reconocimiento de la multiculturalidad del planeta y la necesidad de protegerla de su previsible desaparición. Fue asî como se adoptó el Convenio n. ${ }^{\circ} 169$ de 1989 que rápidamente fue ratificado por una importante cantidad de Estados, sobre todo en Suramérica ${ }^{10}$.

Una de las principales características de este documento fue el amplio desarrollo que se le dio al principio de participación, el cual se consagró a lo largo de todo el texto del Convenio. Todo comienza en el artículo sexto, donde se afirma que, "al aplicar las disposiciones del presente Convenio, los gobiernos deberán: [...] consultar a los pueblos interesados, mediante procedimientos apropiados y en particular a través de sus instituciones representativas, cada vez que se prevean medidas legislativas o administrativas susceptibles de afectarles directamente". El Convenio además ordena crear los medios para que los pueblos participen en todos los niveles de decisión, "por lo menos en la misma medida que otros sectores de la población", y que toda consulta que se lleve a cabo se haga a la luz del principio de "buena fe", "de una manera apropiada a las circunstancias" y "con la finalidad de llegar a un acuerdo o lograr el consentimiento acerca de las medidas propuestas".

También hace énfasis el Convenio, para una mayor garantía de preservación de los pueblos originarios, en una consulta previa obligatoria cuando se está frente a la implementación de programas de prospección o explotación de los recursos existentes en sus tierras (art. 15), en materia de enajenación o transmisión de estas (art. 17), y si se trata de la creación de programas de educación, en especial de la enseñanza de su lengua (22, 27 y 28$)$, entre otros asuntos.

9 Sitio web de la orT, consultado el 5/12/2014: http://www.ilo.org/indigenous/Conventions/no107/lang--es/index.htm

10 Perú el 2 de febrero de 1994, Ecuador el 15 de mayo de 1998, Colombia el 7 de agosto de 1991, Bolivia el 11 de diciembre de 1991, Argentina el 3 de julio de 2000, Brasil el 25 de julio de 2002, entre otros. 
De aquí se desprende que estamos en presencia de (i) un derecho a la consulta previa en cabeza de los grupos étnicos, como la contracara de la "obligación" de su celebración; (ii) que debe ser realizado cuando exista una afectación directa de la comunidad; (iii) a través de las autoridades tradicionales de aquella; (iii) bajo el principio de buena fe; (iv) de manera apropiada a las circunstancias, y (v) con la finalidad de lograr un acuerdo o el consentimiento de los afectados. A nivel internacional, todos estos requisitos van a ser objeto de ampliación o precisión en sucesivos instrumentos internacionales, y de una manera especial en Latinoamérica, por la jurisprudencia de la Corte Interamericana de Derechos Humanos.

En cuanto a los documentos normativos que siguieron al Convenio y lo desarrollaron, el más importante es la Declaración de las Naciones Unidas sobre los Derechos de los Pueblos Indígenas (DNUDPI), aprobada por la Asamblea General de este organismo, en septiembre de $2007^{[11]}$. Aquí se puede apreciar cómo la consulta previa se ve robustecida como una herramienta para defender los grupos étnicos, sobre todo por medio de la exigencia del consentimiento libre e informado como finalidad principal de la consulta o como requisito sine qua non para proceder con ciertas medidas.

En efecto, la DNUDPI afirma que por consulta previa se deberá buscar el consentimiento libre e informado de los pueblos indígenas, antes de "aplicar medidas legislativas o administrativas" que los afecten ${ }^{12}$, especialmente cuando se trata de la explotación de recursos naturales ("minerales, hídricos o de otro tipo") ${ }^{13}$. Pero además, será obligatorio obtenerlo (no sólo buscarlo) cuando se pretende el desplazamiento de una comunidad ${ }^{14}$, y cuando se pretende alma-

11 Si bien se trata de una resolución de la Asamblea General de la onU y, en principio, no tiene efectos vinculantes para los Estados (143 votos a favor, 4 en contra y 11 abstenciones), este documento ha tenido una gran repercusión en Estados (como Colombia) que le han dado cierta recepción en sus ordenamientos internos (ver al respecto: Corte Constitucional de Colombia. Sentencia T-376 de 2012). Sin embargo, cabe anotar que Colombia se abstuvo de votar, y que de la mano de países como Australia, Canadá, Nueva Zelandia, Estados Unidos y Rusia cuestionó la obligatoriedad del consentimiento como un poder de veto, entre otras cuestiones referidas a los territorios y recursos naturales. Ver al respecto: Documento Oficial, Naciones Unidas, Asamblea General, A/61/PV.107, 10 ss.

12 Art. 19: "Los Estados celebrarán consultas y cooperarán de buena fe con los pueblos indígenas interesados por medio de sus instituciones representativas antes de adoptar y aplicar medidas legislativas o administrativas que los afecten, a fin de obtener su consentimiento libre, previo e informado".

13 Art. 32.2: "Los Estados celebrarán consultas y cooperarán de buena fe con los pueblos indígenas interesados por conducto de sus propias instituciones representativas a fin de obtener su consentimiento libre e informado antes de aprobar cualquier proyecto que afecte a sus tierras o territorios y otros recursos, particularmente en relación con el desarrollo, la utilización o la explotación de recursos minerales, hídricos o de otro tipo".

14 Art. 10: "Los pueblos indígenas no serán desplazados por la fuerza de sus tierras o territorios. No se procederá a ningún traslado sin el consentimiento libre, previo e informado de los pueblos indígenas interesados, ni sin un acuerdo previo sobre una indemnización justa y equitativa y, siempre que sea posible, la opción del regreso". 
cenar o eliminar materiales peligrosos en sus asentamientos ${ }^{15}$. Por lo demás, advierte este instrumento que toda privación de bienes culturales, intelectuales, religiosos y espirituales que sufran o hayan sufrido los pueblos indígenas sin su consentimiento, supondrá la obligación de los Estados de establecer "mecanismo eficaces" de reparación, que podrán incluir la restitución, los cuales se acordarán conjuntamente con los pueblos indígenas ${ }^{16}$ (el artículo 28 establece esta misma previsión con énfasis en las "tierras, los territorios y los recursos que tradicionalmente hayan poseído u ocupado o utilizado").

Por otra parte, en el escenario internacional, la jurisprudencia de la Corte Interamericana de Derechos Humanos ha ayudado a develar cómo debe ser ese supuesto escenario de diálogo que implica la consulta previa, afirmando que debe ser realizado: (i) siempre de forma previa, es decir, en la etapa de planeación de la medida que se pretenda ${ }^{17}$; (ii) de buena fe, esto es, con el objetivo de llegar a un acuerdo y no con el afán de cumplir un simple requisito ${ }^{18}$; (iii) de forma adecuada y accesible, o sea que "los gobiernos deberán consultar a los pueblos interesados, mediante procedimientos apropiados y en particular a través de sus instituciones representativas"; además de que (iv) es necesario un estudio de impacto ambiental, que verifique las consecuencias de las medida en el medio ambiente y en la composición de la comunidad, y, por último, (v) la consulta debe ser informada, lo que supone que los pueblos conozcan apropiadamente cuál es la medida que se pretende adoptar y sus repercusiones ${ }^{19}$.

En materia de la obtención del consentimiento libre e informado simplemente como finalidad o como requisito obligatorio para proceder con cualquier medida, la Corte Interamericana, citando al Relator Especial de la onU sobre la situación de los derechos humanos y las libertades fundamentales de los pueblos indígenas y al Comité de las Naciones Unidas para la Eliminación

15 Art. 29.2: "Los Estados adoptarán medidas eficaces para asegurar que no se almacenen ni eliminen materiales peligrosos en las tierras o territorios de los pueblos indígenas sin su consentimiento libre, previo e informado".

16 Art. 11.2: "Los Estados proporcionarán reparación por medio de mecanismos eficaces, que podrán incluir la restitución, establecidos conjuntamente con los pueblos indígenas, respecto de los bienes culturales, intelectuales, religiosos y espirituales de que hayan sido privados sin su consentimiento libre, previo e informado o en violación de sus leyes, tradiciones y costumbres".

17 "Estos procesos de diálogo y búsqueda de acuerdos deben realizarse desde las primeras etapas de la elaboración o planificación de la medida propuesta, a fin de que los pueblos indígenas puedan verdaderamente participar e influir en el proceso de adopción de decisiones": caso Pueblo Indígena Kichwa de Sarayaku vs. Ecuador. Sentencia de fondo y reparaciones del 27 de junio de 2012. Ver también: caso Pueblo de Saramaka vs. Surinam. Sentencia de fondo y reparaciones del 28 de noviembre de 2007.

18 "La consulta no debe agotarse en un mero trámite formal, sino que debe concebirse como 'un verdadero instrumento de participación", "que debe responder al objetivo último de establecer un diálogo entre las partes basado en principios de confianza y respeto mutuos, y con miras a alcanzar un consenso entre las mismas": ibíd.

19 Ibíd. 
de la Discriminación Racial, afirmó que cuando se trata de proyectos de inversión a gran escala, que suponen un impacto profundo en la vida de los grupos étnicos, el Estado tiene la obligación de obtener el consentimiento del pueblo afectado, no bastando con la realización de la consulta ${ }^{20}$.

En el derecho interno colombiano, la bandera de la consulta previa la tiene la Corte Constitucional, que considera que la consulta previa es parte de uno de los tres ámbitos del derecho fundamental de los pueblos indígenas a la libre determinación, que define como el derecho a "determinar sus propias instituciones y autoridades de gobierno; a darse o conservar sus normas, costumbres, visión del mundo y opción de desarrollo o proyecto de vida; y de adoptar las decisiones internas o locales que estime[n] más adecuadas para la conservación o protección de esos fines"21.

Para la Corte, este derecho se compone de tres ámbitos específicos: la participación política de los pueblos en todas las decisiones que puedan afectarlos; la representación política en la máxima corporación pública de elección popular (circunscripciones especiales en ambas cámaras del Congreso de la República), y el reconocimiento de distintas esferas de autonomía, en materia administrativa, territorial y de justicia ${ }^{22}$. En efecto, dentro del ámbito de la participación la Corte Constitucional ubica a la consulta previa, no sin antes advertir que todo depende del tipo de afectación que puedan sufrir los grupos indígenas como consecuencia de la medida que se pretenda adoptar: si la afectación es indirecta, en el sentido de no generar consecuencias directas en la vida de la colectividad, existe entonces sólo una obligación general de participación; sin embargo, si se trata de una medida que acarrea efectos directos sobre el grupo, es obligatorio agotar una consulta previa ${ }^{23}$.

20 "... adicionalmente a la consulta que se requiere siempre que haya un plan de desarrollo o inversión dentro del territorio tradicional Saramaka, la salvaguarda de participación efectiva que se requiere cuando se trate de grandes planes de desarrollo o inversión que puedan tener un impacto profundo en los derechos de propiedad de los miembros del pueblo Saramaka a gran parte de su territorio, debe entenderse como requiriendo adicionalmente la obligación de obtener el consentimiento libre, previo e informado del pueblo Saramaka, según sus costumbres y tradiciones": ibíd., párr. 137.

21 Sentencia T-514 de 2009. Ver además las sentencias SU-383 de 2003, T-973 de 2009 y T-547 de 2010, entre otras.

22 "Se manifiesta en tres ámbitos concretos: (a) el derecho a participar de cualquier decisión que pueda afectar directa o indirectamente los intereses de la comunidad, prerrogativa que se expresa en el derecho a la participación, y concretamente, a de [sic] consulta previa, (b) la participación en las decisiones políticas y (c) el derecho al autogobierno por medio de las autoridades tradicionales": sentencia T-462A de 2014, M.P.: Jorge Ignacio Pretelt. Ver especialmente la sentencia T-973 de 2009.

23 "De este modo, cuando se adopten medidas en aplicación del convenio, cabe distinguir dos niveles de afectación de los pueblos indígenas y tribales: el que corresponde a las políticas y programas que de alguna manera les conciernan, evento en el que debe hacerse efectivo un derecho general de participación, y el que corresponde a las medidas administrativas o legislativas que sean susceptibles de afectarlos directamente, caso para el cual se ha previsto un deber de consulta": sentencia C-030 de 2008. 
El desarrollo de esta figura por la Corte Constitucional ha tenido un impacto vital en el modo específico en el que esta se debe llevar a cabo; en efecto, si bien se encuentra regulada parcialmente en el Decreto 1320 de $1998^{[24]}$, la Corte ha enlistado uno a uno los requisitos especiales que deben satisfacerse para la validez de la consulta, desde luego, con recepción de todos los instrumentos internacionales antes mencionados. Por esto en la jurisprudencia se ha hecho referencia, entre otros, al principio de buena fe que debe regir esta figura, al carácter previo de la consulta, a que se efectúe por medio de las autoridades tradicionales de cada pueblo y a que exista un acompañamiento especial por parte del Estado ${ }^{25}$.

Para efectos de este escrito, a continuación se desarrollan tres de estos requisitos que acercan a la figura al ideal deliberativo que nos interesa y que más adelanten serán retomados (aunque se advierte que la Corte no hace profundización alguna en este aspecto):

(i) La consulta previa debe ser un escenario de diálogo, de concertación, en el cual se puedan explicar los alcances del proyecto y las posibles afectaciones al pueblo indígena respectivo y en donde, por su parte, las autoridades de la comunidad indígena se expresen sobre el asunto ${ }^{26}$. Se sostiene por la Corte incluso que las ideas planteadas en esta discusión deben tener una repercusión en el proyecto final que se iría a ejecutar ${ }^{27}$.

(ii) Afirma la Corte que antes de la celebración de la consulta previa son necesarias unas "conversaciones preliminares" en donde se identifiquen las reglas sobre las cuales se va a construir la consulta previa, comenzando por la determinación de las autoridades que van a estar presentes, por parte de la comunidad, el gobierno y el contratista respectivo ${ }^{28}$.

(iii) Debe buscarse el consentimiento libre e informado de las comunidades, siendo este "indispensable" en los casos que supongan "un alto impacto en las condiciones sociales, culturales y económicas que pongan en riesgo la supervivencia de la comunidad indígena o étnica"29. No obstante, advierte la Corte que esto no les otorga a las comunidades un poder de veto sobre la decisión final que le corresponde al Estado, aunque esta no puede ser arbi-

24 La Corte Constitucional en la sentencia SU-383 de 2003 le ordenó al Gobierno que adecuara este decreto a los requerimientos del Convenio 169 de la orT.

25 Ver, en especial, sentencia C-461 de 2008, respecto de la obligación de la Procuraduría General de la Nación y la Defensoría del Pueblo de acompañar este proceso; y sentencia C-702 de 2010, en cuanto a la característica previa de la consulta.

26 Ver principalmente las sentencias SU-039 de 1997, T-652 de 1998 y T-769 de 2009.

27 Sentencia T-175 de 2009.

28 “... deben existir conversaciones preliminares con la comunidad o comunidades que puedan ser afectadas, con el objeto de identificar las instancias de gobierno y los representantes, socializar el proyecto y concertar la metodología con la cual se adelantará el proceso de consulta previa": sentencia T-462A de 2014.

29 Ibíd. 
traria y debe ser "la alternativa menos lesiva" de acuerdo con el principio de interpretación pro homine ${ }^{30}$.

Hasta aquí se advierte que la consulta previa resulta ser un derecho en cabeza de los pueblos indígenas de participar en las decisiones que los afectan directamente, la cual se debe celebrar de acuerdo con un conjunto de reglas que, en principio, pretenden construir un ambiente de diálogo, de intercambio de posiciones; $y$, finalmente, dependiendo de la posición que se tenga respecto de la obligatoriedad de obtener el consentimiento, puede o no existir la posibilidad de un poder especial de veto dirigido a la autoprotección de los intereses de los pueblos indígenas.

La falta de certeza sobre este último punto y la diversidad de intereses que se encuentran en juego en estos procesos consultivos ha hecho que en su diseño normativo se olvide el punto fundamental, que es la garantía de que efectivamente exista diálogo y que su producto sea aceptable y legítimo para sus destinatarios. Es decir, la principal preocupación alrededor de la estructura de la consulta previa gira en torno a quién tiene la última palabra y, por ende, quién puede vetar a quién, y no en cómo garantizar que se dé un diálogo apropiado y que el resultado sea democrático. Todo ello supone un distanciamiento de esta figura de un verdadero escenario de deliberación, de un diálogo dirigido al consenso sobre lo que es mejor en un determinado territorio o respecto de la explotación de un recurso natural.

Infortunadamente, es más habitual que excepcional encontrarse con un bajo nivel de diálogo y del uso de recursos ajenos a la racionalidad (muchas veces ilegales), para conseguir el consentimiento de los pueblos indígenas o, sencillamente, pasar por encima de sus intereses. Todo lo cual redunda en la desintegración de la cohesión de las comunidades indígenas y en la falta de legitimidad del Estado a la hora de perseguir un supuesto desarrollo económico. Intentos de soborno a los líderes tradicionales, establecimiento de liderazgos paralelos, limitarse a dar información sobre el proyecto sin escuchar a la contraparte u omitir aspectos negativos del mismo, entre otras

30 Ibíd. Ver también la sentencia T-129 de 2011. En este punto es necesario precisar que la Corte en una sentencia anterior parecía acatar la jurisprudencia interamericana, al afirmar que la obtención del consentimiento es un requisito vinculante para el Estado. En efecto la Corte dijo: "Esta corporación aclara que cuando se trate de planes de desarrollo o de inversión a gran escala, que tengan mayor impacto dentro del territorio de afrodescendientes e indígenas, es deber del Estado no sólo consultar a dichas comunidades, sino también obtener su consentimiento libre, informado y previo, según sus costumbres y tradiciones, dado que esas poblaciones, al ejecutarse planes e inversiones de exploración y explotación en su hábitat, pueden llegar a atravesar cambios sociales y económicos profundos, como la pérdida de sus tierras tradicionales, el desalojo, la migración, el agotamiento de recursos necesarios para la subsistencia física y cultural, la destrucción y contaminación del ambiente tradicional, entre otras consecuencias; por lo que en estos casos las decisiones de las comunidades pueden llegar a considerarse vinculantes, debido al grave nivel de afectación que les acarrea": sentencia T-769 de 2009. 
situaciones, es lo que se puede apreciar en lo que concierne a la puesta en práctica de esta figura.

En el caso del pueblo Kichwa de Sarayaku, en Ecuador, se quiso pasar por un proceso de consulta previa, entendida como la simple reunión con algunos miembros del grupo indígena, sin ser estos los representantes de aquella; además de que sólo hubo una información parcial sobre el proyecto de exploración petrolera. Lo anterior fue objeto del fallo de la Corte Interamericana que protegió a esta comunidad. Pero también se han visto estas prácticas en Colombia, por ejemplo con los pueblos Emberá katío y U'wa (en conflicto con la Empresa Arco y la oxy); en Perú, cuando se omitió la consulta en la aprobación de unas normas referidas al TLC con Estados Unidos, situación que terminó con el fallecimiento de 33 personas en una confrontación entre los nativos y la policía en junio de 2009 (sucesos conocidos como "El Baguazo" o "Masacre de Bagua"); y en Bolivia, en el "Territorio Indígena Parque Nacional Siboro Sécure (TIPNIS)", con la exploración de Repsol y la iniciativa del presidente de construir una carretera en este territorio ${ }^{31}$.

Es así como la realidad de la consulta previa dista mucho de las características normativas antes mencionadas, y se reduce a una simple etapa formal, mientras que los grupos indígenas, llenos de esperanza por el mecanismo reconocido, se refugian en la protección internacional, cuando no tienen el apoyo de órganos judiciales fuertes con la capacidad de hacer cumplir la ley. Si bien esta institución busca trazar puentes de comunicación entre el Gobierno y los pueblos indígenas, sólo ha logrado diseñar una figura al interno de la cual no se resuelven conflictos sino que se acentúan, reduciendo la posibilidad de un escenario de diálogo a un discusión sobre quién puede imponerse respecto de su contraparte.

\section{EL PASO DE UN ESCENARIO DE NEGOCIACIÓN COERCITIVA \\ A UN ESCENARIO DE NEGOCIACIÓN DELIBERATIVA}

Desde la perspectiva de este artículo, se advierte que la consulta previa representa en su aplicación: primero, un proceso de abierta confrontación entre, por una parte, un Gobierno y/o un agente privado (que tienen por finalidad la explotación económica de un recurso) y, por otra, una comunidad tribal que busca proteger su identidad cultural y su integridad territorial. Segundo, una disputa de poderes entre la obligatoriedad de la expresión del consentimiento de los pueblos indígenas (como lo sugieren los estándares internacionales) y la pretensión de que se mantenga como una simple finalidad (como parece indicar la práctica de la figura y la posición de los Estados).

31 Grupo Internacional de Trabajo sobre Asuntos Indígenas, IWGiA. "Convenio 169 de la ort, los desafíos de su implementación en América Latina a 25 años de su aprobación”. José Aylwin y Leonardo Tamburini (eds.). Dinamarca, 2014. 
Desde la filosofía política dedicada a la democracia deliberativa, la consulta previa así presentada implica: (i) un escenario de discusión entre antagonistas con intereses particulares, y (ii) una lucha por el poder para amenazar o usar la fuerza de una parte sobre la otra para incidir en el resultado de la discusión. Para el ideal "deliberativo" clásico, en donde se parte de la base de participantes libres e iguales que discuten sobre lo que cada uno supone es el bien común, bajo la guía de la racionalidad y la justificación de la posición propia (entre otras condiciones), la consulta previa así concebida no podría ser denominada deliberativa, ni sería apta para lograr un verdadero consenso, precisamente por la presencia de intereses individuales y la posibilidad de alguna de las partes de ejercer un poder sobre la otra.

En efecto, dentro del ideal deliberativo la racionalidad del resultado se encuentra en directa relación con el grado de efectividad de las condiciones del "ideal discursivo"; de esta forma, entre mayor igualdad e imparcialidad haya en los participantes, mayor apertura del proceso habrá (nadie y ninguna información puede ser excluido); y entre menor coerción se ejerza entre los participantes y estos puedan ser guiados por el mejor argumento, habrá mayor probabilidad de encontrar el bien común ${ }^{32}$. Dentro de la consulta previa, la defensa de intereses individuales, como aquellos referidos a la propia identidad cultural o la necesidad económica de explotar un recurso natural, iría en desmedro de la imparcialidad de los participantes; de la misma forma que el posible veto de los pueblos indígenas o la adopción discrecional de la decisión por el gobierno (ejercicio de poder) tendría como corolario la imposición de un resultado determinado.

No obstante, esta noción de deliberación clásica es transformada por el concepto de "negociación deliberativa", acuñado por MANSBRIDGE y los otros autores del ya citado trabajo The Place of Self-Interest and the Role of Power in Deliberative Democracy ${ }^{33}$. Bajo esta concepción la figura de la consulta previa sí puede ser considerada un espacio de deliberación, en donde los participantes expresan su interés propio y es permitido el ejercicio de cierto grado de poder (todo bajo ciertas restricciones), manteniéndose dentro de un "ideal normativo" ${ }^{34}$ de democracia deliberativa.

En este orden de ideas, se propone repensar el diseño de la consulta previa enunciado anteriormente, con miras a adecuarlo al ideal de negociación deliberativa, lo que supone identificar en qué circunstancias puede existir

32 Mouffe, C. Deliberative democracy or agonistic pluralism? Social Research. Vol. 66, n. ${ }^{\text { } 3, ~ F a l l ~} 1999,747$ y 748.

33 Ob. cit., 7.

34 Elegí "ideal normativo" como traducción a la expresión "regulative ideal", que es el término escogido por estos autores para denotar que la "negociación deliberativa presentada por ellos es un concepto que permite juzgar la realidad teniendo en cuenta su mayor o menor cercanía a su contenido. 
deliberación aun cuando las partes defiendan intereses individuales, y cómo regular el uso del poder dentro de estos escenarios.

\subsection{La consulta previa como un escenario deliberativo de expresión del interés individual}

Advierte Mansbridge que existe cierto grado de aceptación en la doctrina sobre cuáles son los requisitos básicos de la deliberación, cánones que son en sí mismos muy claros y que representan el contenido básico de estos escenarios democráticos: (i) la deliberación debe estar abierta a todos aquellos a quienes va a afectar la decisión, (ii) los participantes deben estar protegidos por unos derechos básicos, (iii) deben tratarse con mutuo respeto y con igual consideración, (iv) deben escucharse mutuamente y exponer sus puntos de vista con razones que puedan ser comprendidas y aceptadas por el otro, (v) deben tener como objetivo la búsqueda de términos justos de cooperación entre personas libres e iguales, y (vi) deben hablar con la verdad.

El primer paso para la transformación de la consulta previa que se propone es considerar que este contenido básico de la deliberación es perfecto para darle mayor precisión al principio ampliamente mencionado de la "buena fe", lo cual no está lejos de la concepción del mismo que se puede extraer de los instrumentos internacionales y la jurisprudencia antes aludida. Estas reglas básicas, al llenar de sentido la exigencia de buena fe en la consulta previa, les permiten a las partes conocer y entender con mayor precisión cómo deben comportarse y qué exigir de su contraparte en el desarrollo de esta figura.

Además, es necesario que los participantes entiendan que estos requisitos están relacionados entre sí, y que entre más apegado esté el diálogo a estos cánones, mayor legitimidad y validez tendrá el resultado y, por ende, más cerca se estará del ideal normativo de la deliberación.

Ahora bien, como se advirtió anteriormente, la noción de deliberación tradicional adicionaba a los anteriores requisitos: (i) la imposibilidad de que los participantes defendieran sus intereses individuales en el proceso deliberativo, debido a la búsqueda del bien común como principal resultado de la discusión, y (ii) que todos los participantes debían tener las mismas oportunidades de influenciar la discusión, de donde se derivaba la necesaria ausencia de poder de coerción en cabeza de las partes. En este aparte nos dedicaremos a resolver el primer inconveniente.

Se sostiene que es absolutamente plausible que dentro de un escenario deliberativo se llegue a un acuerdo entre dos partes que defienden intereses individuales, y para ello se proponen cuatro tipos de "acuerdos comunicativos" planteados por MANSBRIDGE y otros, que son fruto de escenarios de diálogo en los que es posible la expresión del interés particular de los participantes, dentro de lo que denominan los autores citados "una negociación sin coer- 
ción", lo cual entra dentro del ideal normativo de deliberación (negociación deliberativa).

Es así como las partes de la consulta previa pueden buscar uno de los siguientes cuatro tipos de acuerdo, a la hora de expresar sus propios intereses: acuerdo por convergencia, acuerdo teóricamente incompleto, negociación integradora y negociación plenamente cooperativa:

Acuerdos por convergencia son aquellos en que las partes llegan a un consenso en la deliberación, es decir, se encuentra una solución y, además, las partes comparten las mismas razones que la sustentan. Esto se da en la medida en que al llegar a la deliberación las partes conocían sus propios intereses pero no aquellos de la contraparte, y el acceso a la información suministrada por el opuesto les permite comprender la convergencia de sus posiciones y consensuar una salida.

Acuerdos teóricamente incompletos son aquellos en los que, si bien los participantes comienzan con posiciones encontradas, se llega a una misma solución consensuada pero por diferentes razones y dejando abierta la puerta al debate de ciertos aspectos. En estos escenarios se expresa el interés individual de cada parte y existe en estos una contradicción, sin embargo, es posible una solución común, aun cuando existan ciertos puntos que no logren resolverse y cuya discusión se difiera a una deliberación futura. Este tipo de acuerdos muestra gran respeto por la diversidad y permite eficiencia en la decisión de los aspectos más importante, aun cuando se conserven contradicciones en las posiciones de las partes.

La negociación integradora es aquella que es también conocida como 'ganar-ganar' (win-to-win solutions), y se refiere a aquellas posiciones que en un principio eran opuestas entre sí, pero que se logran congeniar al descubrir una tercera vía que satisface los intereses de ambas partes. En este tipo de acuerdos se reconoce finalmente que el desacuerdo entre las posiciones era sólo aparente, si bien únicamente mediante la deliberación es posible advertir las diferencias e idear una solución win-to-win.

Por último, las negociaciones plenamente cooperativas son aquellas en las que las partes tienen intereses contrapuestos, no hay vías alternativas que satisfagan a ambas, pero por medio de un acuerdo distributivo en el que se renuncia a parte de los propios intereses se consigue una solución mejor que el statu quo y que la posición de la contraparte. En esta forma de acuerdo la deliberación también resulta crucial para determinar aquella solución que permita un equilibrio entre ganancia y pérdida y que suponga un beneficio con respecto a la situación actual o aquella planteada por la contraparte.

Si se parte de la base de una consulta previa que busque en primer lugar el consenso, estos cuatro tipos de acuerdo comunicativo se descubren como opciones válidas y que satisfacen a las partes en conflicto, lo que nos permite superar la discusión de si el consentimiento es o no obligatorio y concentrarnos en lo realmente importante: la expresión democrática de las partes 
en conflicto, con respeto de los intereses de los pueblos aborígenes y de la consecución de un desarrollo económico sostenible.

Ahora bien, queda por recordar que, según MANSBRIDGE y otros, este interés particular que se expresa en estas formas de acuerdo comunicativo, para que sea válido y acorde con la deliberación, debe además estar restringido (i) por los límites universales del comportamiento moral y los derechos humanos y (ii) por los límites de la deliberación ya mencionados, tales como el respeto mutuo, la equidad, la reciprocidad, la justicia y la justificación mutua.

Sobre todo debido al primero de los límites mencionados, en la consulta previa no debe perderse de vista que una de las partes en este escenario posee una cultura especial, diversa, que supone otras reglas morales. Desde ese punto de vista, se propone que el límite moral se aborde desde cada cultura, es decir, las autoridades de los pueblos indígenas deben actuar dentro del comportamiento moral que su propia cultura exige, sin dejar de lado una base común positivizada y compuesta por los derechos fundamentales reconocidos en cada ordenamiento jurídico ${ }^{35}$. En cuanto a la segunda restricción, como ya se vio anteriormente, dentro de la consulta previa estos límites se convierten en el contenido de la denominada "buena fe".

Como se puede apreciar, entonces, esta noción de "negociación deliberativa" permite un diálogo que adicione, a la finalidad exigida a las partes por la noción clásica de la deliberación (perseguir un "bien común"), la expresión y defensa de los intereses individuales de aquellas, sin que por ello deje de hablarse de deliberación. Si dentro de la consulta previa encontramos un diálogo que consigue congeniar los intereses de las partes en cualquiera de los "acuerdo comunicativos" mencionados, estaremos frente a un espacio de deliberación.

No obstante lo anterior, para lograr este trascendental cambio, no es suficiente poner a disposición de las partes la información referido al tipo de acuerdos comunicativos antes descritos; el problema no es de falta de información, es también un asunto de diseño normativo, ya que de nada sirve la reflexión sobre el tipo de acuerdos a los que pueden llegar las partes en una consulta previa respetando cánones deliberativos, si normativamente no se ajusta la finalidad normativa de esta figura como se pasa a desarrollar a continuación.

35 El punto es que no puede acusarse a una etnia específica de actuar por fuera de los límites de una moral general, si les atribuye, por ejemplo, a los recursos naturales (la flora o la fauna) un valor igual de importante que a los seres humanos, siempre que esto no suponga la justificación para violar el derecho a la vida o a la integridad de una persona o cualquier otro derecho humano fundamental. 


\subsection{El consenso y la clarificación (o estructuración) del conflicto como finalidades principal y secundaria de la deliberación}

Como se mencionó anteriormente, el otro gran escollo que debe enfrentar la consulta previa para acercarse a la deliberación se refiere a que todos los participantes deben tener las mismas oportunidades de influenciar la discusión, por lo que es necesario que no exista poder alguno de coerción en cabeza de las partes.

En este punto encontramos la principal contradicción entre el ideal deliberativo y el diseño normativo de la consulta previa en los diferentes textos jurídicos. En efecto, si se parte de la base de un supuesto diálogo en el que la finalidad es obtener un "consentimiento previo e informado", como lo expresa el número 2 del artículo 32 DNUDPI, o como lo dice el artículo 6 del Convenio 169 de la огт, "llegar a un acuerdo o lograr el consentimiento acerca de las medidas propuestas", se está partiendo de la negación del diálogo, ya que desde el diseño de la institución se dice cuál debe ser el resultado. A esto hay que sumarle la voluntad política de los Estados, los cuales, por el contrario, pretenden que la consulta previa sea un requisito meramente formal, es decir, apuntan a reducirla a una reunión en la que se le hace una pregunta a un grupo étnico y, con independencia de la respuesta, la decisión se toma como un acto discrecional del Estado.

En otras palabras, la consagración normativa de la consulta previa, en lugar de fomentar el intercambio cultural de un diálogo deliberativo de este tipo, le advierte a los Estados que el problema entre tomar la decisión y ejecutarla se encuentra en convencer a los pueblos originarios; la finalidad se centra en el convencimiento del otro, independientemente de la racionalidad de las posiciones en juego. Lo importante es cuán hábil soy para convencer -en donde entra cualquier tipo de medida que se les ocurra a las partes para este fin-, y no la validez de mis argumentos y el beneficio real de lo que se pretende. Esto, desde luego, tuvo como principal reacción de los Estados, primero, negarse a aceptar que el consentimiento sea necesario y, segundo, ejecutar consultas previas superficiales que se convirtieron en un paso formal más en el proceso de la contratación estatal.

De esta forma, es la misma norma la que establece como eje de la discusión el asunto sobre quién tiene el poder de imponerse sobre quién, por lo que se borra de un plumazo la posibilidad de convertir esta institución en un escenario democrático.

Con base en ello, se propone que las normas jurídicas que reconocen y desarrollan la consulta previa prevean que se trata de un proceso democrático en el que se debe llegar a un consenso entre las partes, por lo menos como principal finalidad de esta figura. En este sentido, se elimina, en principio, la posibilidad de que cualquiera de las partes pueda influenciar directamente el resultado de este diálogo. El consenso como finalidad convierte este ins- 
trumento en un escenario deliberativo, más aun cuando en el punto anterior se indicó que dos partes con intereses incluso contrapuestos pueden llegar a un acuerdo que las beneficie a ambas.

Ahora bien, sería terriblemente ingenuo considerar que un cambio en la finalidad de la consulta previa lograría solucionar los enormes conflictos que puede haber entre el interés de explotar un recurso natural y la defensa de la identidad cultural y de la integridad territorial de un grupo étnico. Por esta razón, la norma debe considerar una finalidad subsidiaria al consenso: es decir, cuando llegar a una solución unánime entre las partes no sea posible, la norma debe insistir en una solución democrática y lo más deliberativa posible. Se insiste en que la finalidad de la deliberación no tiene que ser necesariamente el "consenso sustantivo", también puede tenerse como una finalidad válida la clarificación o estructuración del conflicto, es decir, que las partes logren la identificación de los puntos irresolubles entre sus posiciones.

Una norma jurídica que contemple este tipo de salidas le otorga a la consulta previa su máxima capacidad democrática, debido a que, primero, se exige la deliberación y, por ello, el consenso, y como esto no siempre es posible, se insiste en que al menos, como resultado de este diálogo, se identifiquen plenamente los puntos específicos en los que no fue posible ningún tipo de acuerdo. La precisión de tales aspectos es el perfecto punto de partida para que se entre a una fase de decisión en donde la deliberación está agotada pero no la democracia, y así se llega a los denominados "mecanismos democráticos no deliberativos".

Siguiendo a MANSBRIDGe y otros, ya varias veces citados, se proponen dos escenarios de este tipo: (i) el voto no unánime y (ii) la negociación entre antagonistas que cooperan; la adopción de cualquiera de estos mecanismos debe ser el resultado de un consenso. Es decir, como un primer punto en esta siguiente fase, se debe comenzar por decidir cuál es el mecanismo no democrático que se va a utilizar y cómo se pretende desarrollar, y esto debe ser el resultado de la deliberación en la fase anterior. La unanimidad en este aspecto dotará de legitimidad la decisión final, y hará que sea aceptada por todas las partes ${ }^{36}$.

(i) El voto: este es uno de los más importantes mecanismos democráticos no deliberativos que existen en la política, además, en este mecanismo continúa existiendo discusión sobre las posiciones en juego; sin embargo, esto no se da en medio de un escenario de deliberación, sino que depende

36 Anteriormente se resaltaba cómo la Corte Constitucional de Colombia establecía la importancia de celebrar unas "conversaciones preliminares" para fijar las reglas metodológicas de la consulta previa. Esta finalidad subsidiaria propuesta podría tener un aliado en esta característica de la consulta previa que fijó esta corporación, ya que, además de que se acuerden los parámetros a seguir en la deliberación, se podría tomar una decisión sobre qué mecanismo democrático no deliberativo podría usarse en el momento en que no sea posible el consenso y se hayan precisado los puntos irresolubles entre las partes. 
del ciudadano dotado de virtud pública, es decir, comprometido e interesado en las decisiones políticas que se adoptan a su alrededor. Este ciudadano discute con su entorno social las diversas posiciones que existen, toma una decisión y acude a las urnas.

En cuanto al uso del voto en la consulta previa, se debe partir de la base de que en esta institución se da la participación de pocas partes (pueblos indígenas y Estado, o pueblos indígenas, multinacionales y Estado), por tanto, de llegarse a utilizar este mecanismo, se propone ampliar el número de intervinientes llamando a todo aquel que aun indirectamente pueda resultar afectado por el fondo del asunto en discusión. En ese sentido, existen al menos tres opciones de intervinientes: autoridades estatales independientes (de medio ambiente o de protección a los derechos humanos), organizaciones no gubernamentales que trabajen en la zona o con interés en el asunto, y/o ciudadanos no indígenas que también habiten estos territorios.

Una vez se aumenta el número de participantes como base para la votación, el siguiente paso es decidir cuánto valor se le da al voto de cada interviniente o el tipo de mayoría que se va a utilizar, sin perder de vista que se debe ser respetuoso con la minoría étnica en favor de quien se celebra la consulta previa; considero que lo importante en este punto es lograr representaciones proporcionales de cada parte.

(ii) La negociación entre antagonistas que cooperan: esta es otra posibilidad de arreglo no deliberativo, pero que bajo ciertos presupuestos puede tener una legitimidad democrática. En el trabajo de MANSBRIDGE y otros se argumenta que esta finalidad se logra cuando las partes tienen igual oportunidad de presionarse entre sí, es decir que todos en el debate están en condiciones de prevalecer por medio de mecanismos de poder, ya sea recurriendo al uso de la fuerza o a la amenaza para persuadir a la contraparte. Según estos autores, cuando ambas partes tienen mecanismos de presión que pueden incidir en el resultado, hay una posibilidad de diálogo, debido a que el resultado de dos fuerzas contrarias equivalentes es que se anulan entre sí, lo que deja abierta la vía de la deliberación.

Este es el escenario ordinario de la consulta previa que hoy en día prevalece, por lo menos en Colombia. Esta última opción de "antagonistas que cooperan" supondría un acercamiento a la realidad actual, en donde la necesidad o no del consentimiento es el eje central y depende del grado de afectación que pueda presentar la comunidad étnica correspondiente.

Según la jurisprudencia de la Corte Constitucional colombiana, antes mencionada, obtener el consentimiento es obligatorio cuando existe un "alto impacto en las condiciones sociales, culturales y económicas que pongan en riesgo la supervivencia de la comunidad indígena o étnica". Sin embargo, esto no significa un veto para la administración de los recursos naturales por parte del Estado, quien debe tomar la decisión menos lesiva y más justifica- 
da, de acuerdo con el principio pro homine $e^{37}$. Aquí lo que se observa es un intento por graduar la obligatoriedad del consentimiento, dependiendo del tipo de afectación a la comunidad; una búsqueda orientada a minimizar los riesgos de perjuicio respecto de la comunidad étnica respectiva, pero a su vez permitiendo que la administración pública actúe bajo ciertas circunstancias.

En este escenario, teniendo en cuenta que al menos nos encontramos ante unos puntos que fueron identificados como irresolubles en la etapa deliberatoria, se propone que en la negociación que va a tener lugar entre las dos partes dispuestas a usar su poder para decidir el resultado, exista el acompañamiento de una autoridad imparcial que haga un análisis detenido de los estudios de impacto ambiental y étnico que debieron satisfacerse al inicio del proceso de la consulta, para que con esta herramienta se pueda llegar a un mejor arreglo.

No se trata de que una autoridad ajena al proceso decida definitivamente en uno u otro sentido, sino de ayudar a definir el ejercicio del poder entre las partes, de acuerdo con los efectos previsibles en la naturaleza y sobre la integridad cultural y territorial de la comunidad indígena.

Como se puede apreciar, el uso del poder en estos procesos de decisión no deliberativa supone aceptar la realidad de los conflictos humanos, en donde, sin importar la calidad del debate que se dé, siempre se van a vislumbrar aspectos en los que no es posible un consenso. Allí, se insiste, es menester que por medio de la misma deliberación se defina, primero, los puntos específicos en los cuales no es posible el acuerdo y, segundo, qué camino democrático se puede seguir para lograr una decisión definitiva. Ahora bien, se advierte que el límite de cualquier proceso decisorio siguen siendo los derechos fundamentales de los participantes, que de ningún modo podrán verse afectados por la decisión definitiva.

\section{CONCLUSIONES}

El estudio sobre el lugar que pueden ocupar el interés individual y el poder en un escenario deliberativo representa una gran oportunidad de redefinir la importante figura de la consulta previa, con el objetivo de acercarla al ideal normativo de la negociación deliberativa. El trabajo de MANSBRIDGE y otros nos otorga esa posibilidad.

La visión conflictiva en la que la realidad ha ahogado esta importante herramienta de protección de la identidad de los pueblos aborígenes nos pone en el dilema de la obligatoriedad o no de la obtención del consentimiento de esa comunidad, para que un Estado pueda proceder en la ejecución de un proyecto que prioriza el desarrollo económico. La deliberación puede ser 
la respuesta para superar este dilema y, en ese sentido, crear un espacio de intercambio cultural que favorezca a los intervinientes.

Ahora bien, la definición normativa de la consulta previa que establece al consentimiento de la comunidad étnica como finalidad de la consulta previa, como lo hacen el Convenio 169 de 1989 de la oIT y la Declaración de las Naciones Unidas sobre los Derechos de los Pueblos Indígenas, no hace otra cosa que negar la posibilidad de diálogo entre las partes, debido a que establece como eje de esta figura la obtención del consentimiento de los pueblos afectados y, en algunos casos, la obligación del mismo. Esto supone un desincentivo del diálogo, y la lucha constante entre el poder de veto que, como es natural, va a ser reclamado por los pueblos indígenas en cualquier oportunidad, y el esfuerzo de los Estados por decidir discrecionalmente.

En este sentido, la opción que se propone es acercar esta figura al ideal normativo de la negociación deliberativa, por medio de: (i) una comprensión de la buena fe como depositaria de los cánones básicos de la deliberación, en los que la doctrina tiene pacífico acuerdo; (ii) la exploración de los tipos de acuerdo comunicativo que permiten la expresión del interés individual en la deliberación (convergencia, acuerdo teóricamente incompleto, negociación integradora, negociación plenamente cooperativa); (iii) la consagración normativa del consenso como principal finalidad de la consulta previa, y (iv) la fijación como finalidad subsidiaria de la estructuración del conflicto (identificación de los puntos irresolubles entre las partes) y la decisión consensual de un mecanismo de decisión no deliberativo (el voto o la negociación entre antagonistas).

La visión anterior de una consulta previa deliberativa, lejos de ser una idea acabada, es un intento por acercar esta figura a la riqueza discursiva que posee la deliberación, que es un aspecto de la filosofía política que presenta un gran desarrollo doctrinal, con un sinnúmero de autores que han estudiado en detalle esta vital expresión democrática. Queda abierta la puerta para sugerencias que de forma más acuciosa puedan moldear la consulta previa hacia propuestas más o menos cercanas a estos postulados.

BIBLIOGRAFÍA

Corte Constitucional de Colombia. Sentencia T-380 de 1993.

Corte Constitucional de Colombia. Sentencia SU-039 de 1997.

Corte Constitucional de Colombia. Sentencia T-625 de 1998.

Corte Constitucional de Colombia. Sentencia SU-383 de 2003.

Corte Constitucional de Colombia. Sentencia C-030 de 2008.

Corte Constitucional de Colombia. Sentencia C-461 de 2008. 
Corte Constitucional de Colombia. Sentencia T-175 de 2009.

Corte Constitucional de Colombia. Sentencia T-514 de 2009.

Corte Constitucional de Colombia. Sentencia T-769 de 2009.

Corte Constitucional de Colombia. Sentencia T-376 de 2012.

Corte Constitucional de Colombia. Sentencia T-462A de 2014.

Corte idh. Caso Pueblo de Sarmaka vs. Surinam. Sentencia de Fondo y Reparaciones, 28 de noviembre de 2007.

Corte idh. Caso Pueblo Indígena Kichwa de Sarayaku vs. Ecuador. Sentencia de Fondo y Reparaciones, 27 de junio de 2012.

Fung, A. y E. O. Wright, Deepening Democracy Institutional Innovations in Empowered Participatory Governance. London-New York: Verso, 2003.

Grupo Internacional de Trabajo sobre Asuntos Indígenas, iwgia. "Convenio 169 de la OІт, Los desafíos de su implementación en América Latina a 25 años de su aprobación". José Aylwin y Leonardo Tamburini (eds.). Dinamarca, 2014.

Grupo Internacional de Trabajo sobre Asuntos Indígenas, ingia. "El Mundo Indígena 2014”. CÆCILIE Mikkelsen (comp. y ed.). Dinamarca, 2014.

Habermas, J. Between Facts and Norms, Contributions to a Discourse Theory of Law and Democracy. Cambridge, Mass.: The мiт Press, 1996.

Mansbridge, Jane; James Bohman, Simone Chambers, David Estlund, Andreas Føllesdal, Archon Fung, Cristina Lafont, Bernard Manin y José Luis Martí. The Place of SelfInterest and the Role of Power in Deliberative Democracy. The Journal of Political Philosophy. Vol. 18, n. ${ }^{\circ} 1,2010,64-100$.

Mouffe, C. Deliberative Democracy or Agonistic Pluralism? Social Research. Vol. 66, n. ${ }^{\circ}$ 3, Fall 1999.

Mouffe, C. El retorno de lo político: comunidad, ciudadanía, pluralismo y democracia radical. Buenos Aires: Paidós, 1999.

Nino, C. S. The Constitution of Deliberative Democracy. New Haven-London: Yale University Press, 1996. 